\title{
Documentário do Rio Fiúza: Material Didático que Possibilita Discussões Mil...
} Documentary of River Fiúza: Teaching Material that Enables Thousands Discussions...

\author{
Cléa Hempe ${ }^{1}$;Denise Miriam Neumann Santos ${ }^{2}$; Valdecir Schenkel ${ }^{3}$; \\ Janete Finger Scheuer'; Temia Wehrmann
}

\footnotetext{
${ }^{1}$ Graduada em Geografia, Especialista em Mídias na Educação, Especialista em Orientação e Supervisão na Escola de Educação Básica, Mestra em Geografia, Professora de Geografia, lotada no MAHP, Tutora do Curso de Especialização em Educação Ambiental (UFSM), Sócia da ARPA FIÚZA, 2a Secretária do Conselho Municipal do Meio Ambiente de Panambi;

${ }^{2}$ Graduada em Geografia, Assistente Administrativa lotada no- MAHP;

3 Graduado em Geografia, Bacharel em Geografia; Professor de Geografia da Rede Estadual e Federal de Ensino;

${ }^{4}$ Graduada em História, Professora de História na Rede Estadual, Professora de História na Rede Municipal, atualmente lotada no MAHP.

5 Graduada em História, Especialista em Educação Especial, Professora de História na Rede Estadual de Ensino , Professora da Rede Municipal, lotada no MAHP como Coordenadora.
}

Resumo

A elaboração e a edição do vídeo intitulado "Documentário do Rio Fiúza" teve por objetivo geral elaborar e disponibilizar material didático pedagógico, mostrando a situação do rio Fiúza da nascente até a foz, a fim de dialogar, mobilizar e conscientizar as comunidades para desenvolver ações de preservação no município de Panambi e região a qual pertence à bacia hidrográfica. Considera-se imprescindível problematizar sobre a importância e as facetas que os recursos hídricos abrangem, juntamente com a importância intrínseca da paisagem, assim como sua multifuncionalidade. Para realização do Vídeo Documentário do Rio Fiúza, buscou-se parcerias com a Secretaria Municipal de Educação e Cultura, Conselho Municipal do Meio Ambiente, Prefeitura Municipal de Panambi (RS), Museu e Arquivo Histórico Professor Hermann Wegermann e Professores Voluntários. Para realização do vídeo Documentário do rio Fiúza, foi utilizado, além de pesquisa bibliográfica, pesquisa de campo, entrevistas, filmagens, análise de vídeos, entre outros. Os organizadores estão satisfeitos com a aceitação por parte das escolas e da comunidade em geral. Neste, é possível explorar uma série de conteúdos, por exemplo: as atividades agropecuárias, áreas de APP's a luz da legislação vigente, uso e ocupações que estão instaladas nas proximidades e que não atendem a legislação, os problemas ambientais iniciando na nascente do rio, entre outras.

Palavras-chave: Material Didático Pedagógico; ARPA FIÚZA; Documentário.

\begin{abstract}
The preparation and editing of the video, entitled "Documentary of the Fiúza River" had the general objective to draw up and provide educational didactic material, showing the situation of the Fiúza River from the spring to its mouth, in order to dialogue, mobilize and instruct the communities to develop actions of preservation in Panambi and the region which belongs to the watershed. It is essential to discuss the importance and the facets that water resources cover, along with the intrinsic importance of the landscape, as well as its multifunctionality. To carry out the Video Documentary of the Fiúza River we sought partnerships with the City Department of Education and Culture, City Council on the Environment, City Hall of Panambi (RS), Museum and Historic Archive Professor Hermann Wegermann and Volunteer Teachers. To carry out the Video Documentary of the Fiúza River we used bibliographical research, field research, interviews, filming, video analysis, among others. The organizers are satisfied with the acceptance by the Schools and the Community in general. In this you can explore a range of contents, e.g.: agricultural activities, areas of APP (Area of Permanent Preservation) in light of the legislation in force, the usage and occupations that are installed in the vicinity and that do not meet the regulations, environmental problems, starting from the river's spring, among others.
\end{abstract}

Keywords: Educational Didactic Material; ARPA FIÚZA; Documentary. 


\section{Introdução}

A ARPA FIÚZA foi criada no ano de 1997 e desde a sua fundação tem como definição de seu próprio nome Associação de Recuperação e Preservação Ambiental Rio Fiúza, ao mesmo tempo homenageia o rio Fiúza como carro-chefe de sua organização.

No ano de 2008 sócios se reuniram e escreveram um roteiro e foi dado início a coleta de materiais como filmagens de atividades realizadas com vistas à preservação ambiental do rio. No ano de 2012, este entrou novamente em pauta e alguns sócios se propuseram a colocar em prática o sonho, isto é, buscar parcerias para formar um grupo para reelaborar o roteiro e fazer a edição do vídeo documentário. Foi realizadas parcerias para elaboração do documentário e no ano de 2013, houve o seu lançamento oficial.

\section{Referencial teórico}

As águas que formam o rio Fiúza brotam de diversas fontes em uma área de banhado situada na localidade de Canta Galo, no município de Santa Bárbara do Sul, num lote de assentamento de reforma agrária realizado pelo INCRA, no ano 1997. Este lote situa-se à margem esquerda da rodovia estadual que liga Santa Bárbara do Sul a Palmeira das Missões, próximo ao Km 15 da RS 508. O rio Fiúza faz parte da Bacia do Rio Ijuí, e esta pertence à Bacia Hidrográfica do Rio Uruguai. É um dos rios brasileiros que compõem uma das 12 grandes Bacias Hidrográficas do Brasil. O relevo de planalto, regionalmente conhecido como coxilhas, é o predominante no território de Santa Bárbara do Sul e de Panambi, no qual se situa a bacia hidrográfica do rio Fiúza. As coxilhas são feições de planalto com topo aplainado alongando-se longitudinalmente nas direções dos cursos d' água (SCHENKEL, 1999).

A Bacia do rio Ijuí, a qual o rio Fiúza pertence abrange territórios de 20 municípios, com uma área de drenagem de $10.649,13 \mathrm{~km}^{2}$ na qual residem 337.249 habitantes. A Bacia do rio Fiúza possui uma área de $190 \mathrm{~km}^{2}$, dos quais $150 \mathrm{~km}^{2}$ situam-se no município de Panambi e 40 $\mathrm{km}^{2}$ no município de Santa Bárbara do sul (ARPA FIÚZA, VIDEO DOCUMENTÁRIO DO RIO FIÚZA, 2013).

A Figura 1 corresponde aos mapas das bacias hidrográficas do rio Ijuí e do rio Fiúza com destaque ao território dos municípios aos quais se inserem. 


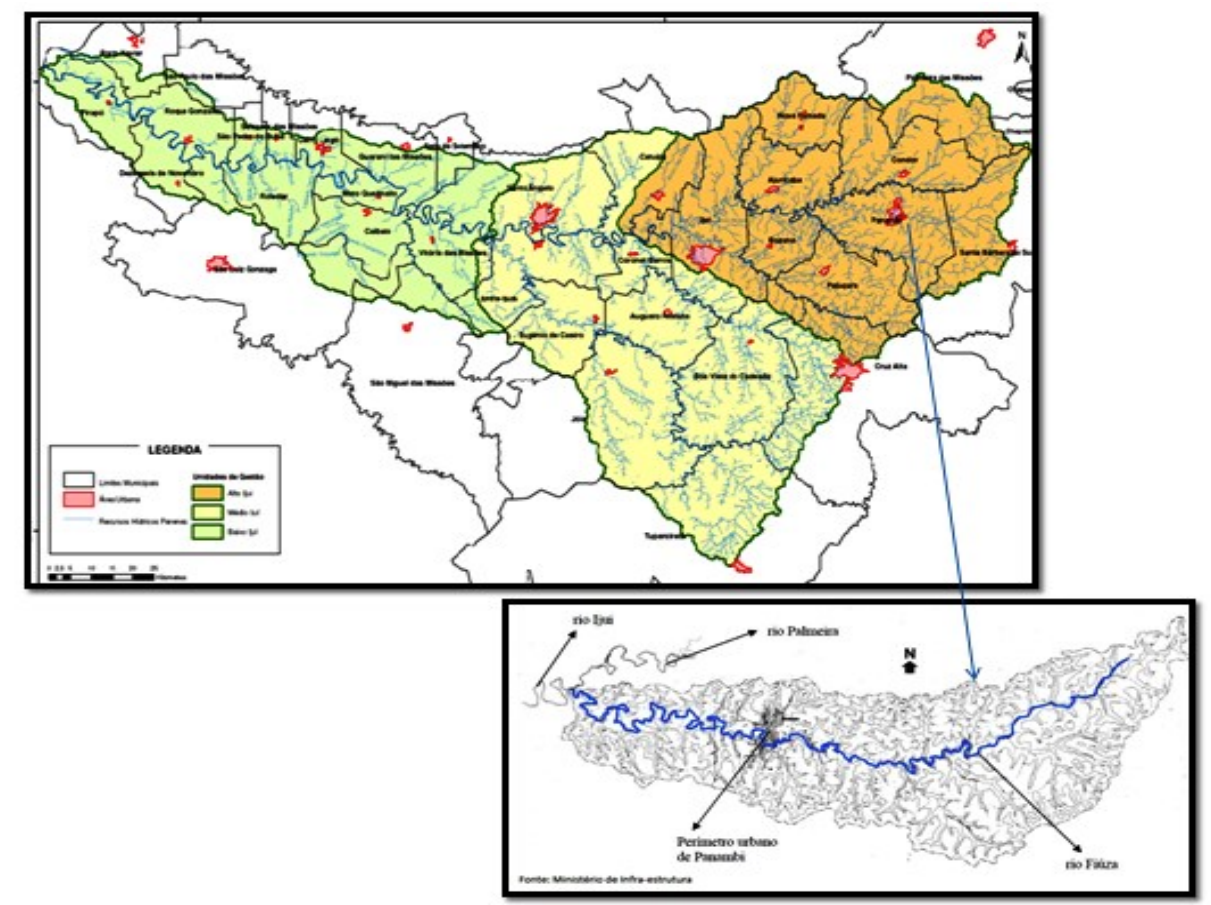

Figura 1 - Mapas das Bacias do Rio Ijuí e Fiúza.

Fonte: ARPA FIÚZA, Vídeo Documentário do Rio Fiúza, 2013.

Na Figura 2, Mapa das Regiões Hidrográficas do Brasil e Mapa das Sub-bacias da Região Hidrográfica do rio Uruguai, pode-se observar a localização da bacia do rio Uruguai no mapa do Brasil e a localização da bacia do rio Ijuí no Mapa do estado do Rio Grande do Sul.

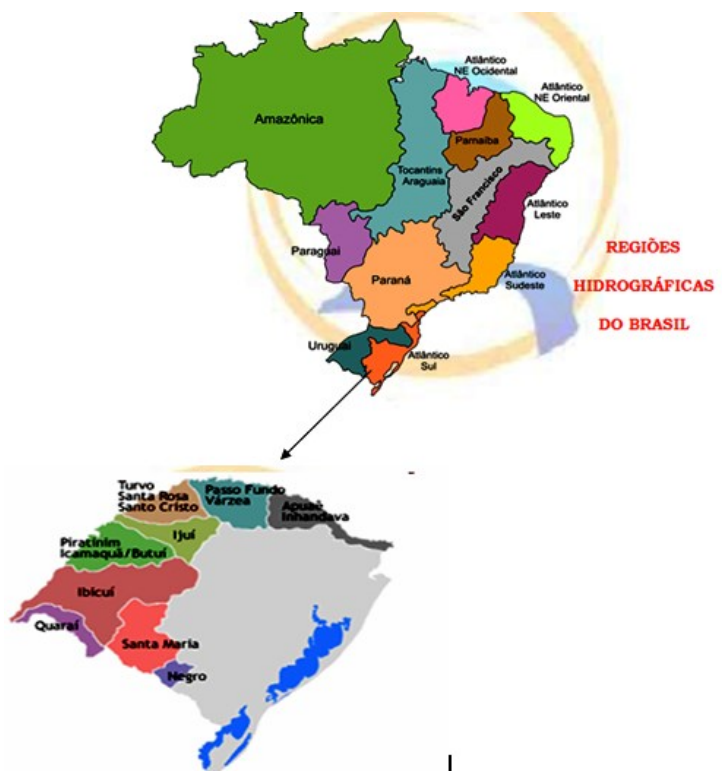

Figura 2 - Mapa Regiões Hidrográficas do Brasil e Mapa das Sub-bacias da Região Hidrográfica do Uruguai Fonte: Palestra, 2011.

A bacia do rio Uruguai é uma das doze regiões hidrográficas do território brasileiro. Possui uma área de $385.000 \mathrm{~km}^{2}$, dos quais $174.612 \mathrm{~km}^{2}$ se inserem em territórios do Brasil, pois ocupa também área da Argentina e Uruguai. Nos estados do Rio Grande do Sul e de Santa Catarina banha terras parciais ou totais de 384 municípios. As principais cidades brasileiras localizadas na bacia são Lages e Chapecó (SC), Uruguaiana, São Borja, Bagé e Santana do Livramento (RS). A região hidrográfica do Uruguai apresenta um grande potencial hidrelétrico, com uma 
capacidade total de produção de $40,5 \mathrm{KW} / \mathrm{km}^{2}$, considerando os lados brasileiro e argentino, uma das maiores relações de energia $/ \mathrm{km}^{2}$ do mundo (PROFILL, PALESTRA, 2011).

Constituem fontes de contaminação das águas superficiais e subterrâneas na região os efluentes da suinocultura e avicultura no oeste catarinense e os agrotóxicos utilizados, principalmente na rizicultura no oeste gaúcho. Também se ressalta o grande assoreamento que ocorre nos afluentes desta bacia em virtude do intenso uso agrícola de suas terras que acarretou desmatamentos desmedidos.

A bacia de drenagem do rio Uruguai e seus afluentes, que tem sua nascente em território catarinense, tomam as direções de escoamento oeste, sul e sudeste, desaguando no estuário do rio da Prata, já fora do território brasileiro.

Há de se destacar o predomínio de população urbana sobre a rural no conjunto dos municípios que formam a região hídrica do rio Uruguai. A partir da análise conjunta, verifica-se que o grau de urbanização médio apresentado é de $79 \%$.

A Figura 3 traz o número de populações urbanas e rurais dos municípios da bacia do rio Ijuí.

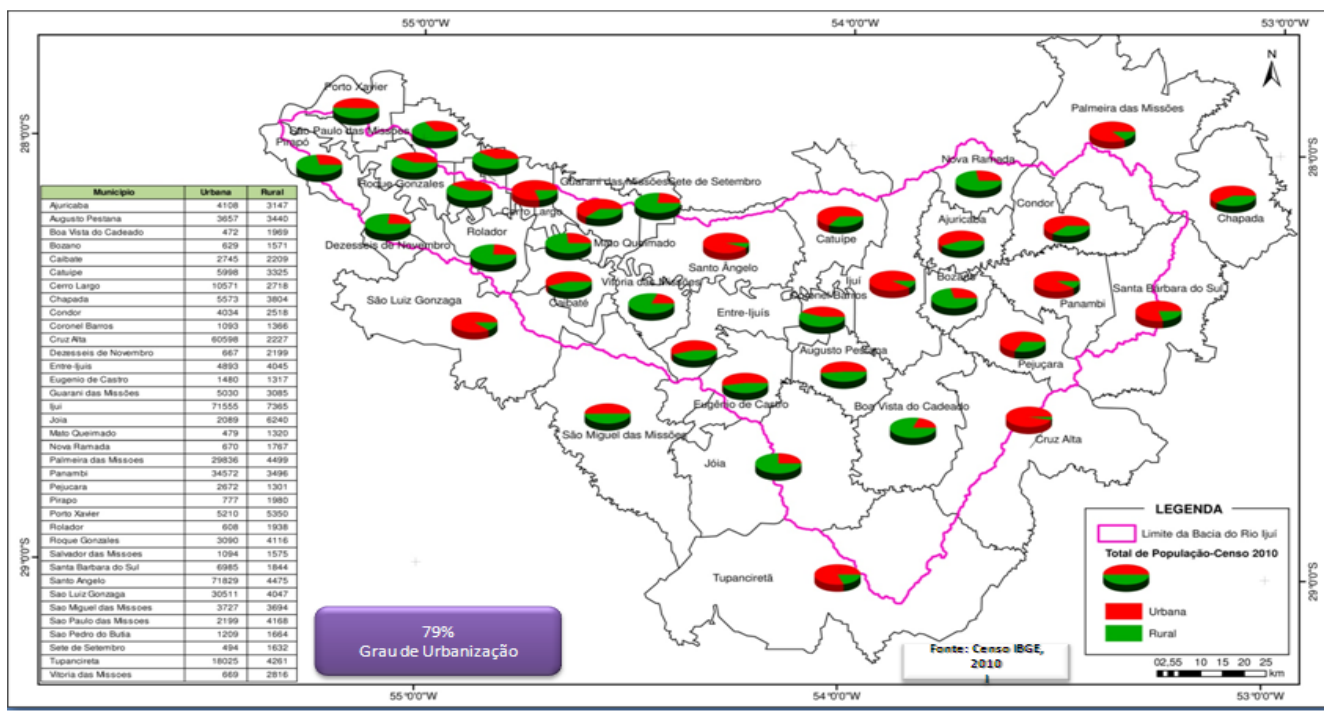

Figura 3 - Populações Urbanas e Rurais dos Municípios da Bacia do Rio Ijuí.

Fonte: PROFILL, Palestra Seminário Municipal do Meio Ambiente, set de 2011.

Ao analisar a distribuição demográfica urbana e rural dos municípios formadores da bacia hidrográfica do rio Fiúza verificou-se que em Santa Bárbara do Sul o valor de taxa de urbanização fica exatamente na média da bacia do Uruguai, com o percentual de $79,1 \%$, enquanto que Panambi apresenta um valor consideravelmente maior, que corresponde a mais de $90 \%$. A Figura 4 apresenta os indicadores destes dados.

\begin{tabular}{|l|r|r|r|}
\hline \multicolumn{1}{|c|}{ Município } & \multicolumn{1}{|c|}{ População urbana } & População rural & \multicolumn{1}{c|}{ População total } \\
\hline Panambi & $34.562(90,8 \%)$ & $3.496(9,2 \%)$ & $38.058(100 \%)$ \\
\hline Santa Bárbara do Sul & $6.985(79,1 \%)$ & $1.844(20,9 \%)$ & $8.829(100 \%)$ \\
\hline
\end{tabular}

Figura 4 - População Urbana, Rural e Total dos Municípios da Bacia do Rio Fiúza.

Fonte: IBGE, Censo Demográfico, 2010.

O processo de urbanização foi conseguindo com o tempo anular a importância dos rios dentro do cenário urbano. Muitas pessoas trabalham e moram próximas as margens, circulam e se divertem junto ao rio e não percebem a importância deste no cenário urbano.

Ao longo da história da humanidade os rios têm sido utilizados como vias de penetração para o interior, facilitando o crescimento de aglomerados urbanos e, que em função da 
A Figura 5 mostra o ponto de captação da água da CORSAN. No caso do rio Fiúza, o grau de importância se eleva à medida que este é o fornecedor do abastecimento de águas para $\mathrm{a}$ concessionária estadual CORSAN, que capta, trata e distribui a água pública no perímetro urbano de Panambi, assim como, conjuntamente com outros afluentes, também mata a sede da população de vários outros municípios na continuação da bacia hídrica dos rios Ijuí e Uruguai. $\mathrm{O}$ município de Panambi caracteriza-se por se uma comunidade de médio porte com aproximadamente 14.618 economias, atendendo a população urbana (AMMES, 2015).

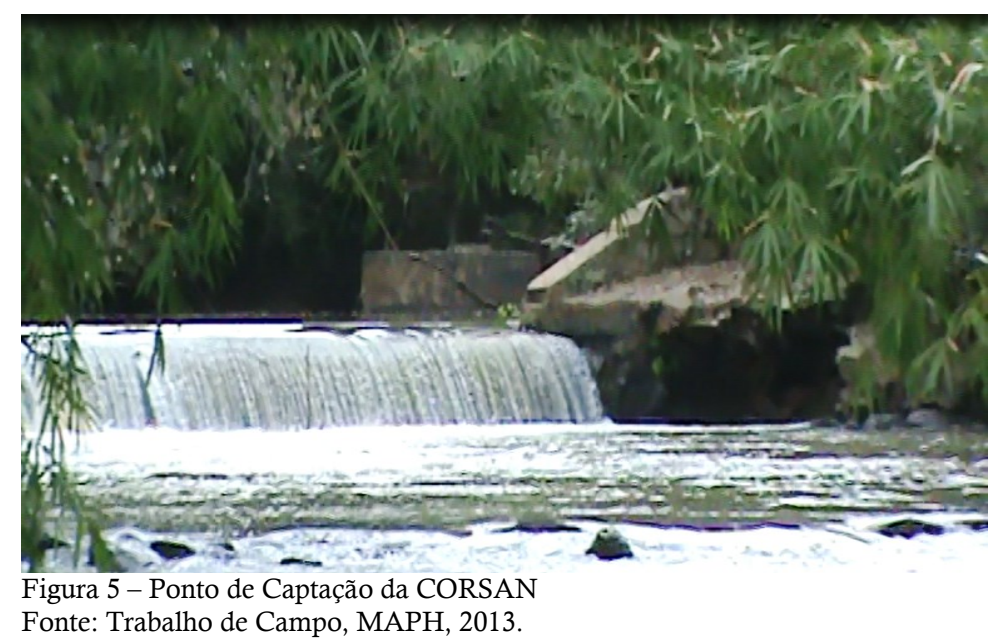

O ponto de captação de água da CORSAN, que abastece a cidade de Panambi, localiza-se próximo a ponte que liga os bairros Pavão e Vila Nova, na zona urbana panambiense. A CORSAN possui uma estação de tratamento de água instalada em Panambi desde o ano de 1970. No decorrer desses 45 anos, o volume de água do rio Fiúza sofreu redução decorrente, essencialmente, ao processo de assoreamento.

Em contato com a CORSAN, apesar de tal modificação apresentada neste período, não oferece restrição à sucção que atualmente chega aos 129 lt/seg como média anual. Esta é realizada por meio de uma barragem de nível com um conjunto de bombas submersas, com vazão máxima de 140 1/s (PANAMBI, PLANO DE SANEAMENTO BÁSICO, 2009).

\section{Metodologia}

Para elaboração do Vídeo Documentário do Rio Fiúza seguiram-se as seguintes etapas: a)Buscou-se parcerias; b) Representantes da ARPA FIÚZA coordenaram os trabalhos do Documentário; c) Foram realizadas reuniões com os representantes das entidades parceiras (funcionários do Museu e Arquivo Histórico Professor Hermann Wegermann - MAHP, representantes da Secretaria Municipal de Educação e Cultura-SMEC, representantes da ARPA FIÚZA, do Conselho do Meio Ambiente e Professores Voluntários); d) Decidiram-se os tipos de pesquisas, métodos e técnicas; e) Delimitaram-se as tarefas para cada segmento representante; f) Realizaram-se reuniões para analisar e discutir o roteiro; g) Realizaram-se a seleção de materiais diversos (documentos, imagens iconográficas, partes de vídeos, etc); h) Realizaram-se novas filmagens aéreas ao longo do leito do rio; i) Realizaram-se novas filmagens terrestres de trechos selecionados do rio; j) Adaptação do roteiro, das imagens e de voz; 1) Edição final; m) Lançamento oficial; n) Distribuição do DVD gratuitamente às instituições de ensino das três redes públicas, ao Conselho do Meio Ambiente, entre outras Entidades. 


\section{Resultados e Discussão}

No Museu e Arquivo Histórico Professor Hermann Wegermann realizaram-se as pesquisas em documentos como registros sobre a vasão do rio Fiúza no século XIX, a história do nome do Rio, relatórios de canalizações de afluentes do Rio, data de construções de pontes, pinguelas, identificação de passos e pontes em mapas, análise de relatórios caracterizando os aspectos físicos da área próxima ao Rio, entre outros dados.

Foram selecionadas e analisadas imagens iconográficas do acervo do Arquivo Histórico relacionadas aos temas: áreas de lazer existentes no século XX na área urbana, imagens de canalizações de arroio do Moinho, o qual deságua no rio Fiúza, áreas com expressiva degradação e interferências antrópicas.

Em relação às entrevistas, professores e funcionários tomaram vários depoimentos com pessoas que tiveram e que têm vivências com Rio em relação à passagem por passos, a lavagem de roupas, aulas de natação entre outros.

A ARPA FIÚZA no ano de 2013 realizou nova filmagem do percurso do rio Fiúza da nascente à foz, aproveitando-se que havia um helicóptero na cidade nas festividades do munícipio. O Conselho Municipal do Meio Ambiente auxiliou com a disponibilização de carro para trabalho de campo para observação de trechos do rio Fiúza, com destaque a sua foz, na confluência deste com o rio Palmeira.

$\mathrm{O}$ roteiro foi reescrito com base num já existente e nos materiais selecionados durante as pesquisas. Após roteiro elaborado, imagens iconográficas, vídeos, filmagens prontas, um locutor de rádio, sócio fundador da Entidade, fez a gravação do áudio-descrição.

A partir desta etapa a ARPA FIÚZA incumbiu o grupo para contratar um profissional para dar continuidade na edição do documentário, pois estes não possuíam recursos técnicos para prosseguir. Os trabalhos de produção do Documentário foram em torno de 250 horas. Para conhecer maiores detalhes sobre as atividades da ARPA FIÚZA, acesse o endereço eletrônico: http://escolaversusprofessor.blogspot.com.br/search?updated-max=2013-11-12T09:09:00-08:00, sala de aula virtual.

Segue Figura 6 (A/B) - Capa do Documentário do Rio Fiúza

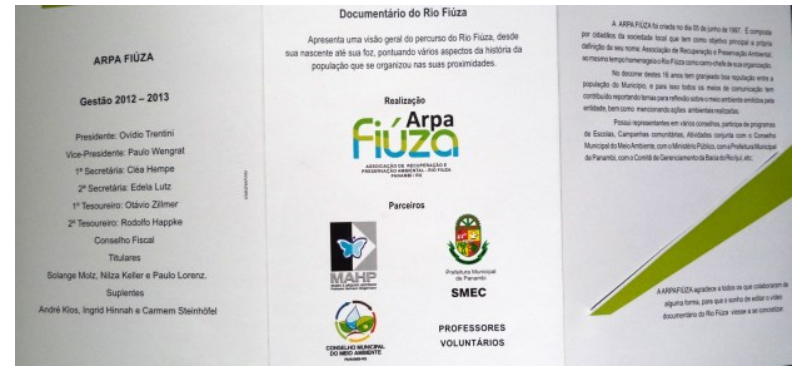

Figura 6 A - Frente da Capa do Documentário do rio Fiúza Fonte: Arquivo da ARPA FIÚZA.

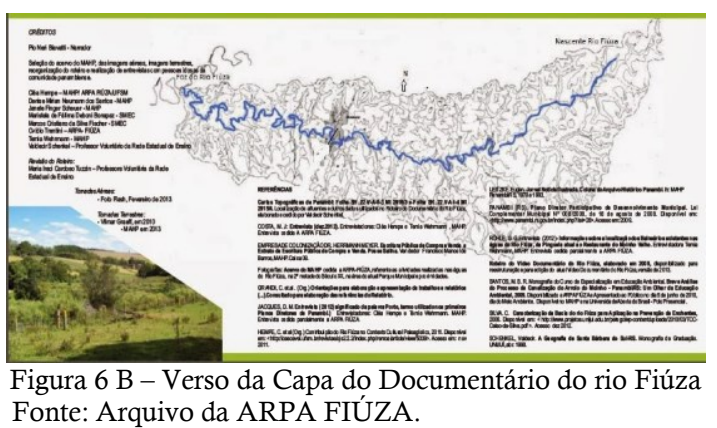

Fonte: Arquivo da ARPA FIÚZA.

O lançamento ocorreu no VIII Seminário Municipal do Meio Ambiente, no dia 23 de setembro de 2013, quando aproximadamente 500 pessoas assistiram o Documentário do Rio Fiúza. Neste dia foi distribuído DVD às pessoas que contribuíram com depoimentos. Veja Figura 7, da direita para esquerda o Senhor Jaime Malheiros da Costa, com a idade de 90 anos. Este ao ser entrevistado disse que passava o rio a cavalo, quando ainda não havia nenhuma ponte sobre o mesmo. 


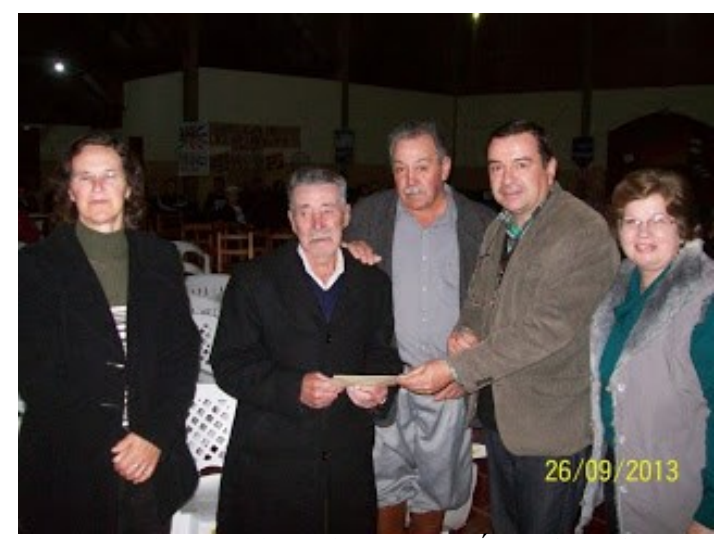

Figura 7- Vice-Presidente da ARPA FIUZA fazendo a entrega do DVD ao Sr. Jaime Malheiros da Costa. Fonte: Arquivos ARPA-FIÚZA.

Alguns dias após o lançamento, o presidente da ARPA FIÚZA, fez a entrega de 100 DVDs para as escolas das três redes e entidades diversas, de forma gratuita. As escolas utilizaram o Vídeo Documentário do Rio Fiúza, como subsídio na Semana da Água que ocorreu no mês de abril de 2014, com apoio da Secretaria Municipal de Educação e Cultura. Este material tem sido utilizado em sala de aula, nas diferentes séries/anos na Educação Básica.

O documentário traz informações valiosas que podem ser trabalhadas com alunos a partir da Educação Infantil ao Superior.

\section{Sugestões de trabalho com educandos}

Como o próprio título do artigo sugere Video Documentário do Rio Fiúza: material didático que possibilita discussões mil..., existem várias possibilidades de exploração deste material didático. A seguir, apresentam-se algumas imagens iconográficas que são apresentadas no documentário complementadas com breve análise e sugestões de trabalho com alunos. Estas são apenas alguns exemplos, outras poderão ser contextualizadas em sala de aula.

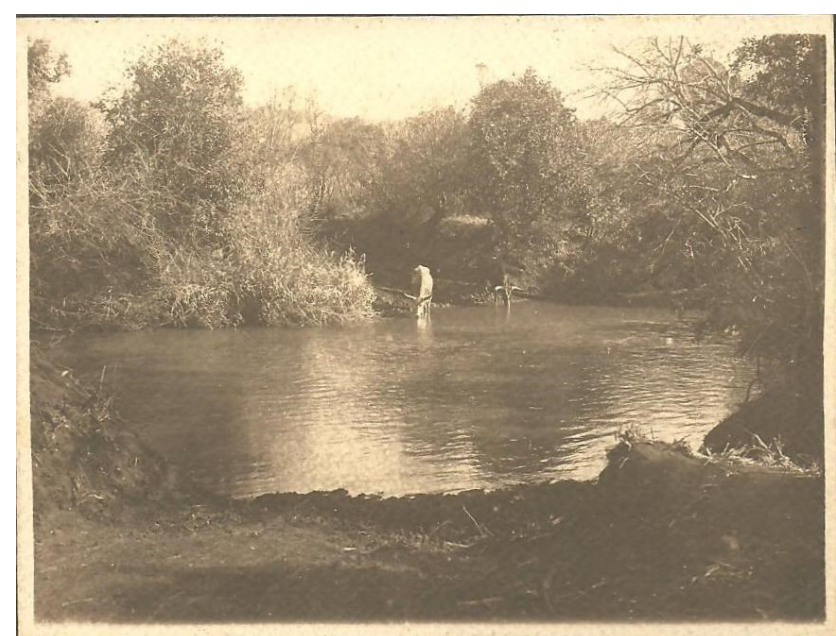

Figura 8 - Imagem de um Passo sobre um rio Fonte: Álbum F 23. Acervo do MAHP

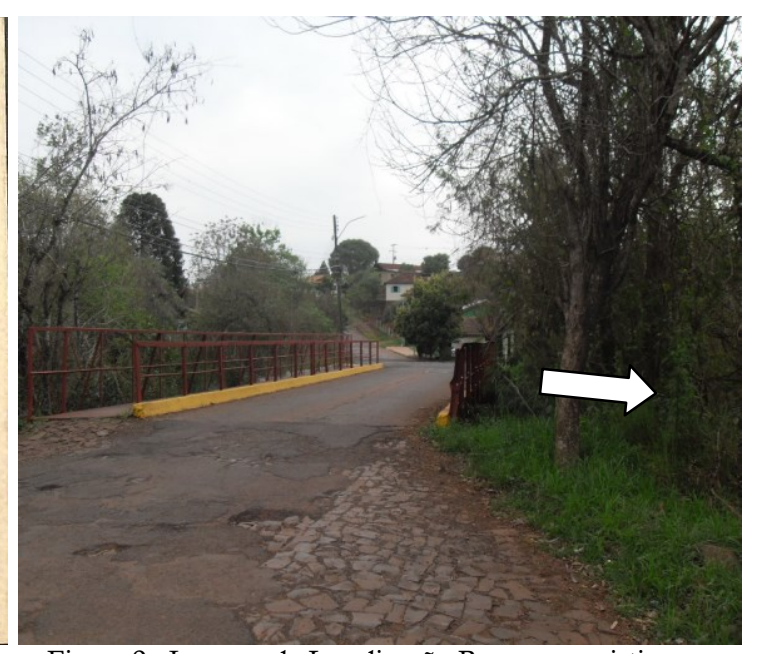

Figura 9 - Imagem da Localização Passo que existia no rio Fiúza

Fonte: Acervo Digital do MAHP

A Figura 8 traz a imagem de um passo em um rio. "A lei municipal $\mathrm{n}^{\circ} 22$, de $1^{\circ}$ de julho de 1955, no seu Art. 140, denomina de Passos, os atravessadores habituais (também conhecidos por meio de barcas ou balsas) para pessoas, animais e veículos, em águas públicas, tais como rios e arroios" (PANAMBI, 1955).

Foi realizado entrevistas com pessoas que atravessaram o rio Fiúza quando este não apresentava nenhuma ponte, os quais relatavam o seu entendimento do que era um Passo e sua importância. Segundo Doralina Jaques, tinha um pequeno Porto de cada margem do rio, passava de carroça, de aranha, a pé por dentro do rio, era como uma rampa dos dois lados do rio. $\mathrm{O}$ 
passo referido pela entrevistada ficava mais ou menos 50 metros à jusante da atual ponte conforme mostra a seta na cor branca na Figura 9.

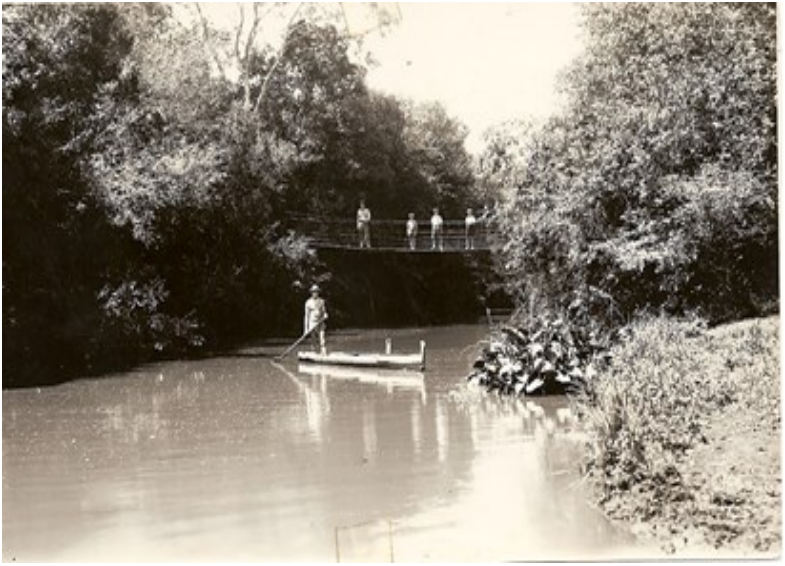

Figura 10 - Pinguela que ligava a rua Pai Tomáz a Avenida Konrad Adenauer

Fonte: Álbum 2.039. Acervo do MAHP

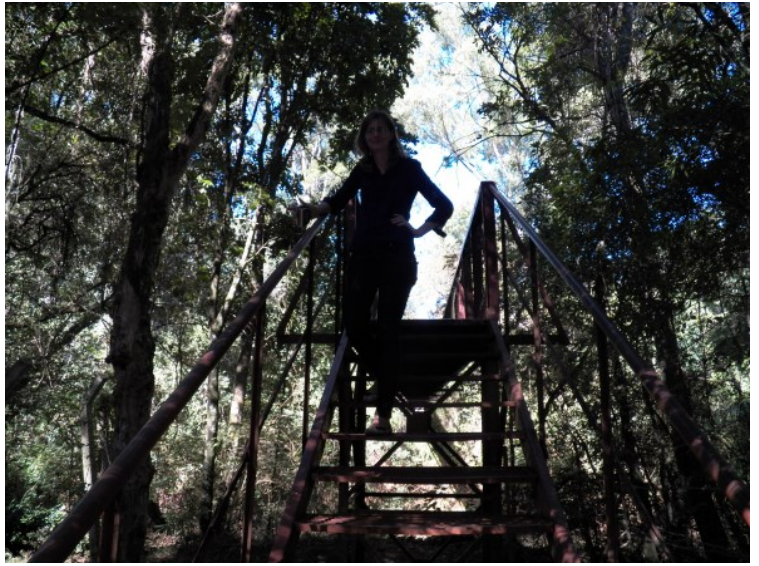

Figura 11 - Pinguela na rua Pai Tomáz Fonte: Autores

A Figura 10 mostra uma Pinguela que foi construída por volta da década de 1950, mais tarde foi construída outra Pinguela ao sul da primeira, visualizada na Figura 11. No ano de 2014, esta foi retirada para construção neste lugar de uma ponte, a qual liga a rua Pai Tomáz à Avenida Konrad Adenauer, veja a Figura 12 A/B, ponte construída.

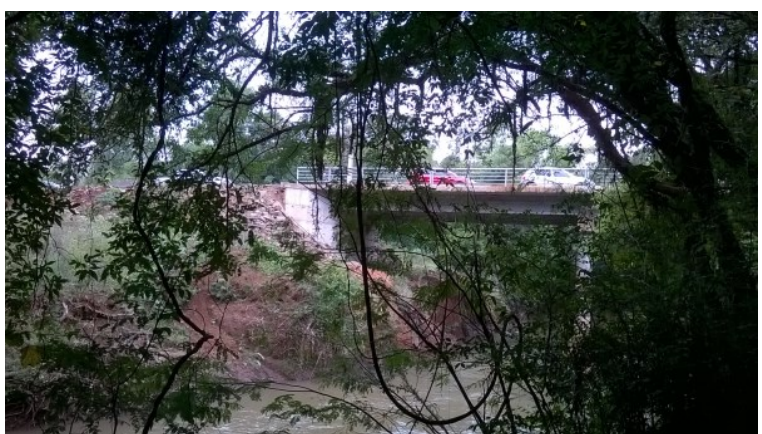

Figura 12A - Ponte construída sobre o rio Fiúza Fonte: Autores

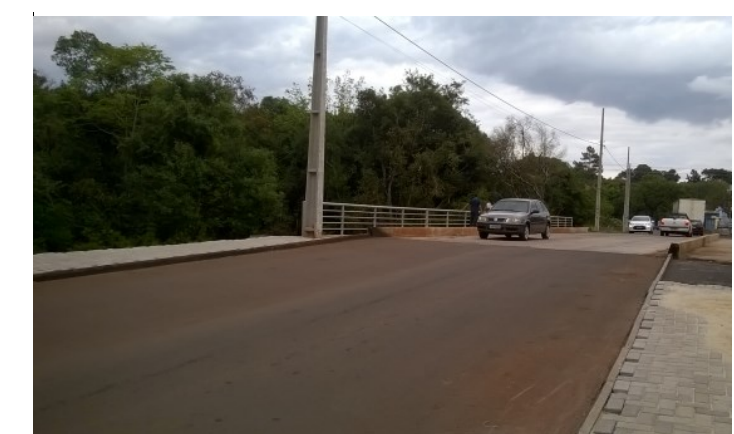

Figura 12 B - Ponte construída sobre o rio Fiúza Fonte: Autores

No MAHP existem diversos documentos que registram aulas de natação nos balneários próximo a pinguela (Figura 10) e na taipa do Moinho Velho (Figura 13). Há a biografia do professor que lecionava na prática a natação, também medalhas, certificados conforme o tempo que o aluno conseguia nadar, entre outros. Existem entrevistas de pessoas que participavam das aulas, registros de localização de balneários públicos e particulares que existiam ao longo do rio Fiúza. 


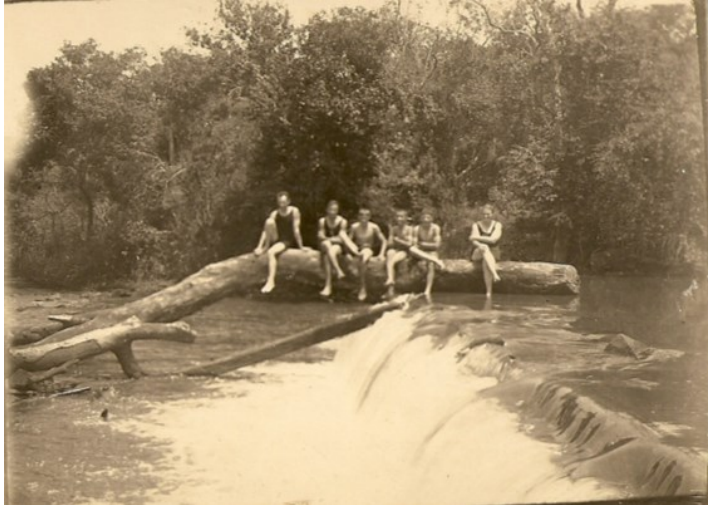

Figura 13 - Balneário no rio Fiúza, próximo a taipa do Moinho Velho

Fonte: Álbum 6.140. Acervo do MAHP

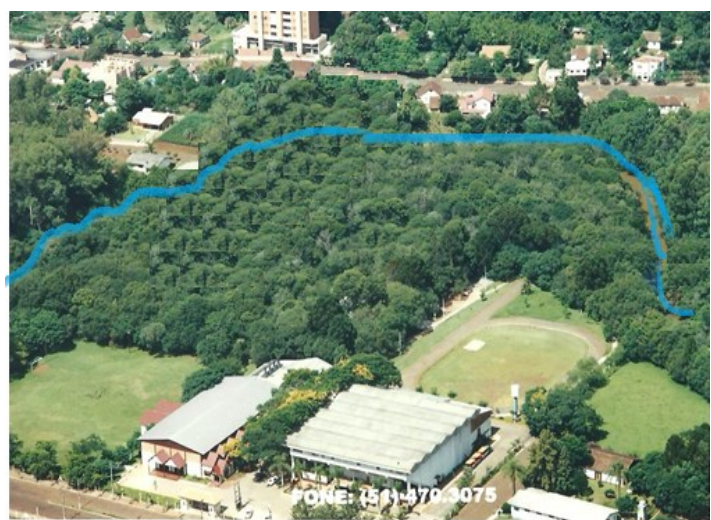

Figura 14 - Vista Aérea do Parque Mun. Rudolfo Arno Goldhardt Fonte: Acervo do MAHP. Foto 15.132, adaptada.

OBS: O traçado do rio foi realizado pelos autores

A Figura 14 corresponde à área do Parque Municipal Rudolfo Arno Goldhardt, neste lugar são realizadas as festividades do município de Panambi. Conhecendo a área é possível observar a existência de uma rica fauna e na flora que poderão gerar muitas pesquisas por estudantes dos diversos níveis de ensino. Nesta aérea, foi construída uma pinguela pela qual se pode chegar a uma ilha resultante de uma ação antrópica. O leito do rio foi alterado, fazendo com que o mesmo seguisse seu percurso em linha reta e não em curva. Segundo notas publicadas nos jornais, a finalidade da ação foi evitar as enchentes. Várias pessoas caminham na ilha respirando o ar puro da natureza. Também é possível a realização de pesquisas neste pequeno espaço (ilha), como estudos das características vegetais, tipos de solo, importância de preservação de margens, assoreamento, lixo e poluição, entre outros.

A Figura 15 apresenta imagem do Google Earth. Segundo Ferreira o Google Earth é um software gratuito,

\begin{abstract}
desenvolvido pela empresa Google, com ferramentas de fácil manuseio, e que disponibiliza imagens de satélites de alta resolução, que nos permite a representação da superfície terrestre de forma que a escala da imagem pode ser simulada, podem ser usadas para observar elementos geográficos, como as áreas urbanas, as áreas agrícolas, a estrutura viária, o relevo, a hidrografia e a vegetação, propiciando também a comparação dos objetos geográficos em diferentes escalas. Observa-se que à medida que simulamos a escala, as feições geográficas ampliam de tamanho, e também, ao mesmo tempo aumentam o nível de detalhe da imagem. Entretanto, a cobertura de imagens no Brasil com bom nível de zoom ainda se limita às maiores cidades. Tudo isso com bastante facilidade, pois se pode afirmar que suas ferramentas são muito simples e qualquer pessoa pode manusear, basta termos máquinas com internet, para baixar o Google Earth e depois fazer a aplicação do conteúdo com os alunos $(2010$, p.196)
\end{abstract}

Na Figura 15 mostra exemplo de atividade que poderá ser realizada com alunos. A imagem do Google Earth foi adicionada fotos de trabalho de campo. A partir das imagens é possível analisar as alterações na paisagem, além de vários outros temas de discussão. 


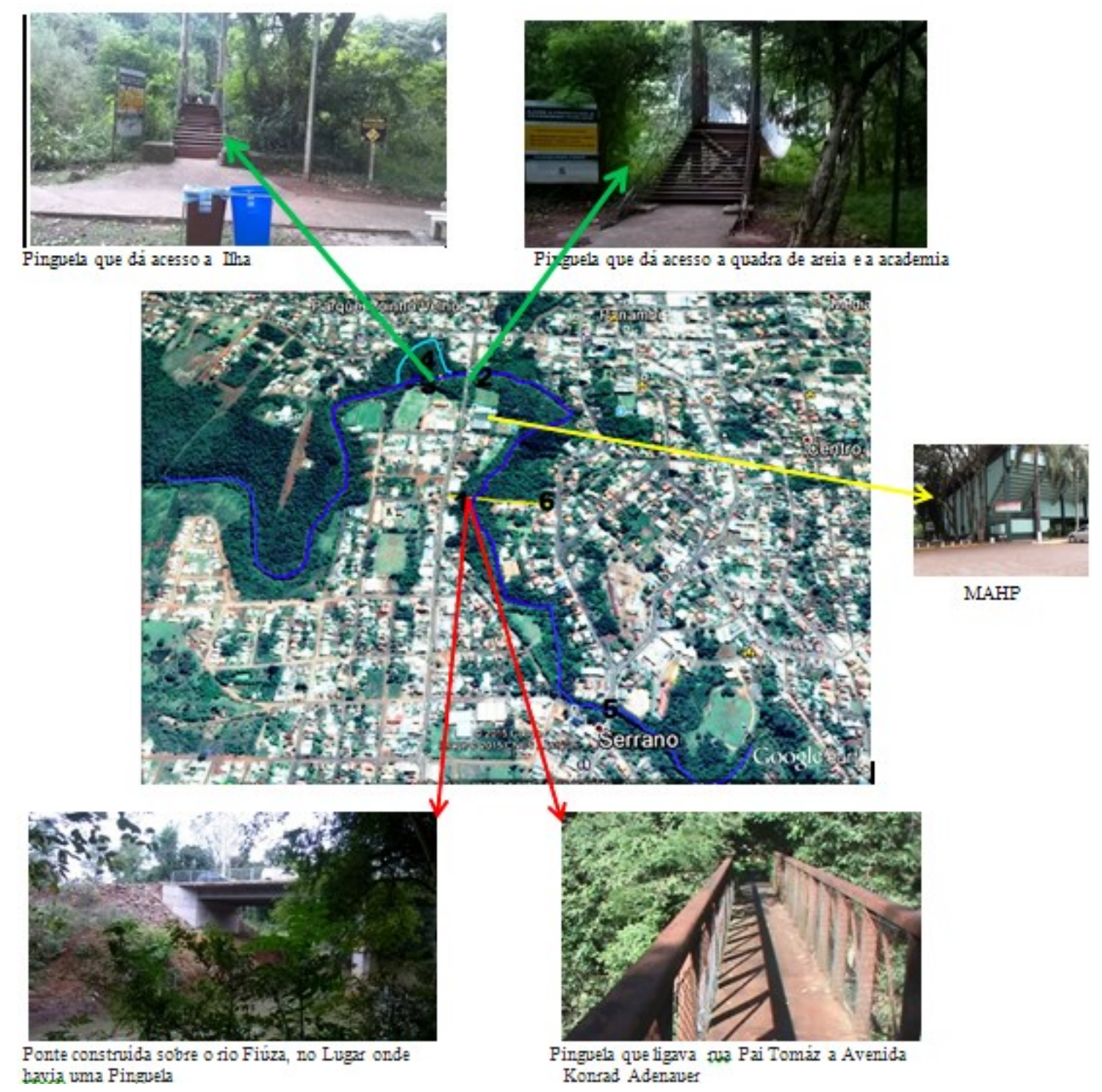

Figura 15 - Imagem do Google Earth e fotos tiradas pelos autores e cedidas por particulares.

Organização: Autores

\section{Conclusão}

Os organizadores do Vídeo Documentário do Rio Fiúza estão satisfeitos com a aceitação por parte das escolas e da comunidade em geral. A partir deste, é possível explorar uma série de conteúdos, por exemplo: as atividades agropecuárias, áreas de APP's à luz da legislação vigente, as atividades que estão instaladas nas proximidades e que não atendem a legislação, os problemas ambientais, iniciando na nascente do rio, entre outras.

O documentário foi mais uma das ações realizadas pela ARPA-FIÚZA para servir de subsídio de pesquisa a alunos, professores e comunidade em geral e ao mesmo tempo recuperar, preservar e divulgar a história do rio que corte a cidade no sentido leste-oeste.

\section{Referências}

AMMES, Pedro. CORSAN. Informação verbal, 09 abr. 2015. 
ARPA FIÚZA, Vídeo Documentário do Rio Fiúza, 2013. Disponível no Museu e Arquivo Histórico Professor Hermann Wegermann.

\section{FOTOGRAFIAS: Acervo iconográfico do MAHP.}

BERGAMIM, Juliane Stenzinger; GOLO, Cristiomar; HEMPE, Cléa; MORONI, Alberto Yates. A Contribuição do Rio Fiúza no Contexto Cultural Paisagístico. Revista REMOA. v(7), nº 7, p. 1689 1704, MAR - JUN, 2012

JACQUES, D. M. Entrevista_(dez.2012). Significado da palavra Porto, termo utilizado nos primeiros Planos Diretores de Panambi. Entrevistadores: Cléa Hempe e Temia Wehrmann do MAHP. Entrevista cedida a ARPA FIUZZA.

Mapa do Rio Grande do Sul: Bacias Hidrográficas. Disponível em: < http://www.scp.rs.gov.br/uploads/BaciasHidrograficas.pdf>. Acesso em 15 jun. 2013.

Mapa do Brasil. Disponível Power Point/ Palestra PROFILL, 2011.

Mapa da Bacia do Rio Ijuí. Disponível Power Point/ Palestra PROFILL, 2011.

FERREIRA, Dayane Magalhães. O Software Google Earth aplicado à disciplina de Geografia no $1^{\circ}$ ano do ensino médio da escola de ensino fundamental e médio Professor Luis Felipe, Sobral - CE. Disponível em: <http://www.uvanet.br/rhet/artigos_outubro_2010/google_earth.pdf> Acesso em: 9 abr. 2015.

PANAMBI. Plano de Saneamento Básico Municipal, 2009.

SILVA. C. Características da Bacia Hidrográfica do Rio Fiúza. In: SILVA. C. Caracterização da Bacia do rio Fiúza para Aplicação na Prevenção de Enchentes. Disponível $\quad \mathrm{em}$ : $\quad<$ http://www.projetos.unijui.edu.br/petegc/wpcontent/uploads/2010/03/TCC-Celso-da-Silva.pdf > . Acesso dez. 2012.

SCHENKEL, Valdecir. A Geografia de Santa Bárbara do Sul-RS. Monografia de Graduação. UNIJUÍ, abr. 1998. 